\title{
Hampiqato de Ayacucho símbolo, tradición y patrimonio vital
}

Hampiqato from Ayacucho, Symbol, Tradition and Vital Heritage

Ayakuchupa hampiqatunmanta: Ayllu kawsay, unanchasqa hampi, kawsay patrimonio nisqa

Walter Pariona Cabrera ${ }^{1}$

Universidad Nacional de San Cristóbal de Huamanga, Ayacucho, Perú parionawalter@yahoo.es

\section{RESUMEN}

El propósito de esta investigación es dar cuenta de la existencia e importancia del hampiqato, lo que denominamos «farmacia de origen ancestral» o alterna, donde se ofertan insumos deshidratados de origen natural (plantas, animales marinos, minerales y algunos productos transformados provenientes de la ciudad de Lima), que constituyen recursos para el tratamiento y la ritualidad en los procedimientos de cura de los síndromes culturales con la medicina tradicional. El artículo es una primera aproximación a la interpretación del valor real y simbólico para la gran mayoría de los habitantes del espacio urbano y rural de Ayacucho. La variedad de recursos naturales que se ofertan en el hampiqato constituye la continuidad de procesos inmemoriales de conocimientos y ciencia logrados en el campo de la medicina y son parte importante de la cosmovisión andina.

\section{PALABRAS CLAVE}

Hampiqato, cosmovisión, síndromes culturales, ciencia ancestral y salud

\footnotetext{
1 Estudió Antropología y la carrera de Educación Secundaria en la especialidad de Historia y Geografía en la Universidad Nacional de San Cristóbal de Huamanga de Ayacucho; es magíster en Antropología por la misma universidad. Es doctor en Ciencias Sociales, especialidad de Antropología, por la Universidad Nacional Mayor de San Marcos. Ha publicado el libro Lecturas antropológicas de la cultura en Ayacucho (2004). Publicó artículos de su especialidad en libros y revistas de divulgación. Fue miembro del comité editorial de la revista de estudios andino-amazónicos Alteritas de Ayacucho. Actualmente, es docente principal de la Facultad de Ciencias Sociales de la Universidad Nacional de San Cristóbal de Huamanga de Ayacucho.
} 


\section{ABSTRACT}

The goal of this research is taking in account the existence and importance of Hampiqato. This is a place, usually called as «pharmacy of ancient origin» or alternative pharmacy, offers natural products (plants, marine animals, minerals and some processed products from Lima city). The treatment and ritual procedures for healing cultural syndromes use these resources. This research is a first approach to understand the real and symbolic Hampiqato's value for the most of rural and citizen inhabitants of Ayacucho. Such variety of natural resources offered in the Hampiqato makes evident the continuity in the transmission of medicine knowledge and science from ancient times. In addition, shows these resources as important part of Andean cosmovision.

\section{KEYWORDS}

Hampiqato, cosmovision, cultural syndromes, ancient science and health

\section{PISILLAPI QILLQASQA}

Kay qillqasqawanqa yachasunchik hampiqatumantan. Chaymi kan kunan pachapiqa «ñawpa hampina» sutiwan riqsisqa. Hampiqatuqa pachamamapa rurunmi (llapa ima rurukuna, añawikuna, chakisqa añawikuna, tukuy chakisqa qurakuna, quchamanta uywakunapas, chakisqa chaIlwakuna, qiqllakuna, huklaya Lima llaqtapi rurusqakunapas). Kunan pacha runakunaqa kayna tukuy rurukunawan hampinku ima unquytapas. Chaynatapuni ruwaraku ñawpaq pachapipas, ñawpaq runakunaqa. Kay qillqasqawanqa asuykuyta atisunchik Ayakuchumanta runakunapa yachasqanman hampiqatumanta.

\section{TIQSI RIMANAKUNA}

Hampiqatu, ñawpaq yachay, hampiy, hampiy yachana

\section{Introducción}

El actual proceso de globalización como fenómeno mundial genera transformaciones nunca antes vistas en el planeta. La ciudad de Ayacucho es el escenario de rápidos cambios socioculturales; se caracteriza por ser una sociedad de consumo como cualquier otra ciudad del Perú. En los últimos cinco años hemos asistido al incremento de numerosas farmacias que ofertan medicamentos de diferentes marcas y precios, pero 
lo más notorio es la proliferación de las llamadas farmacias naturistas, que ofrecen desde medicamentos industrialmente procesados hasta hierbas deshidratadas y embolsadas, como boldo, chancapiedra, cola de caballo, entre otras, para restablecer la salud. Pareciera el retorno a la valoración y el uso de recursos naturales en el campo medicinal, solo que esta aparente ilusión brilla por los precios altos para el alcance de la gran mayoría de la población ayacuchana, lo que evidencia que hoy vivimos envueltos por la ley de la oferta y la demanda propia de la sociedad neoliberal eminentemente mercantilista.

La investigación explora el hampiqato (que traducido al español significa «farmacia de origen ancestral», porque en estos espacios se ofrece una amplia variedad de productos naturales de origen animal, vegetal y mineral), con la finalidad de relevar la importancia de este espacio permanentemente demandado por los usuarios.

El crecimiento de la población ayacuchana y la influencia de culturas foráneas no han mellado totalmente la persistencia de paradigmas diferentes sobre las percepciones de salud y enfermedad. Las enfermedades propias de nuestras culturas denominadas síndromes culturales o síndromes de filiación cultural ${ }^{2}$ están presentes en la memoria de gran parte de los actuales pobladores de Ayacucho. Esta realidad se corresponde con la existencia del hampiqato ubicado en el primer mercado de abastos de la ciudad, en la calle Carlos F. Vivanco. Los quioscos del hampiqato ofrecen recursos naturales que sirven de insumo para la prevención, el diagnóstico y la cura de los síndromes culturales.

Es necesario señalar que en los mercados de reciente formación, como los de Nery García y los del asentamiento humano Las Américas, se pueden observar también pequeños espacios de la «farmacia ancestral». Este hecho muestra que la población de las zonas periurbanas de la ciudad necesita de estos insumos naturales para el tratamiento de muchas enfermedades y males populares.

\section{Sociedad y salud, breve aproximación al contexto}

En un país multicultural como el nuestro, no es fácil la convivencia armoniosa entre las culturas existentes. En los grupos sociales dominantes del país aún se mantienen discursos que apelan al esencialismo, cuando no a posturas etnocéntricas (en términos de autopercibirse como el

2 Autores como Carlos Zolla y otros (1988, p. 31) usan el concepto de «síndrome de filiación cultural» definiéndolo como «aquellos complejos mórbidos que son percibidos, clasificados y tratados conforme a claves culturales propias del grupo y en los que es evidente la apelación a procedimientos de eficacia simbólica para lograr la recuperación del enfermo». 
mejor o «superior» en el aspecto social) y racistas. Ideas prejuiciosas sobre lo cholo, indio, pobre y marginal aún existen en el imaginario de muchos ciudadanos de sectores económicamente opulentos y no opulentos. Las diferencias sociales y la exclusión de los sectores pauperizados de nuestra sociedad por el Estado peruano atenta contra nuestra cultura andina. Aquellos sectores desinformados sobre la historia y los procesos culturales de nuestro pasado no entienden que en el espacio andino se desarrolló la ciencia y tecnologías muy avanzadas desde la presencia de civilizaciones como Caral ${ }^{3}$. Por ello, considerar que la ciencia y los conocimientos científicos solo puede ser atributo de las sociedades occidentales bajo el supuesto de que conocieron la escritura no tiene ningún asidero en la actualidad.

La antigua población andina, con sus logros científicos y tecnológicos, fue capaz de resolver necesidades sanitarias individuales y colectivas, muchas de las cuales hoy están vigentes. Este hecho ha posibilitado la continuidad de la existencia del hampiqato («farmacia popular» de origen ancestral), que no es exclusivo de nuestra localidad, sino que existe hasta en las ciudades cosmopolitas, como es el caso de Lima (la capital del Perú), La Paz (capital de Bolivia), entre otras.

Algunos síndromes culturales, como Urqupa qawasqan (mal generado por el irrespeto a las deidades andinas), qayqa (mal que se produce por el contacto o cercanía con el alma del recién fallecido), ñati («estómago movido de su lugar» por accidente o esfuerzo desmedido), pacha alcanzo y aya pincha (males producidos por la Pachamama o emanaciones de sustancias tóxicas existentes en la naturaleza como producto de sustancias descompuestas), entre otros, fueron estudiados y conocidos minuciosamente por los antiguos médicos andinos. Los procedimientos de prevención, diagnóstico y tratamiento de estos males en la actualidad los realiza el hampiq, continuador de los médicos ancestrales, y los recursos o insumos necesarios para restablecer la salud se consiguen, en su gran mayoría, en el hampiqato del mercado Carlos F. Vivanco de la ciudad de Ayacucho.

El hampiqato es un lugar de particular importancia en el proceso de resistencia y recreación cultural para el uso y la adquisición de recursos curativos naturales de origen vegetal, animal y mineral, y también algunos productos industrializados, como pócimas revitalizadoras, jarabes rejuvenecedores, y para males de órganos internos, como riñones, estómago, hígado, vesícula, etc.

3 «Caral fue el centro administrativo religioso más importante de una sociedad que se asentó a lo largo del valle del río Supe en la costa norcentral del Perú. Floreció en el Formativo inicial entre los años 2900 y 1800 a. C.» (Editorial Septiembre, 2015, p. 26). 
El proceso político de las últimas décadas, en el campo de las políticas públicas de salud, nos permite afirmar que el etnocentrismo de la mayoría de los grupos sociales dominantes y de aquellos que gobiernan el país ha mantenido indiferencia y nulo interés por la investigación de los saberes ancestrales en el campo de la salud. Es cierto que existen cambios, pero no se corresponden con el contexto actual y las necesidades de salud en el Perú.

La ausencia de investigaciones sobre el hampiqato en Ayacucho nos motivó a indagar sobre este problema; este reto nos obliga a construir reflexiones y argumentos epistemológicos basados en datos empíricos de primera mano. En ese proceso, consideramos que «muchas de las experiencias que se llevaron a cabo en la región andina y en el Perú han apuntado a la recuperación o la revaloración de los conocimientos de la medicina tradicional, sin ir mucho más allá de la simple descripción del fenómeno y de sus posibles aplicaciones (el uso de hierbas o plantas medicinales). Otros han intentado «intercalar» algunas prácticas tradicionales en el sector moderno de atención, como ha ocurrido con la atención del parto (posición vertical y disposición de la placenta) o la administración de hierbas medicinales en la atención primaria. Los esfuerzos de racionalización e integración de prácticas tradicionales en los sistemas oficiales de atención han sido escasos, de corta duración y baja aceptabilidad entre los médicos y otros profesionales de salud, y han resultado casi siempre en la subordinación de la medicina tradicional al sistema oficial o en el empobrecimiento del efecto terapéutico y de la eficacia simbólica» (2009, p. 58).

Consideramos que en nuestra realidad regional aún pesa mucho lo que Guillermo Lumbreras Ilama el trauma colonial ${ }^{4}$, que no se trata solo de la desestructuración del sistema económico social y político del antiguo Tahuantinsuyo, sino del proceso irracional de olvido, el rechazo y la vergüenza de los conocimientos desarrollados en aquel espacio cultural andino. En el caso de la salud, a muchos profesionales les cuesta entender este proceso, tal vez por su desinformación de hechos históricos culturales desarrollados desde nuestras civilizaciones originarias y por la infrecuente reflexión acerca de la categoría epistemología. Los datos etnohistóricos señalan, por ejemplo, que los incas tuvieron especialistas cuya formación médica estaba sustentada en una tradición íntegramente

4 «La extirpación de idolatrías y luego la Inquisición fueron instrumentos represivos destinados a imponer a sangre y fuego la cultura oficial [...] Mataron a todos los sabios indígenas de todos los niveles de sabiduría que existían en el Tahuantinsuyo quedando solo los que pudieron esconderse o huir, de modo que entrado el siglo XVII ya se había eliminado a la élite intelectual andina, habían desaparecido los amautas» (Lumbreras, 2006, p. 76). 
responsable, como personas moral y éticamente probas que poseían una sólida creencia religiosa, lo que garantizaban la atención de calidad a los usuarios.

La adivinación (procedimientos rituales que los españoles no entendían) se practicaba para diagnosticar una enfermedad, determinar la veracidad de una confesión, localizar un bien perdido, identificar a los hechiceros hostiles, escoger entre varias vías posibles, definir el sacrificio más apropiado para una deidad y, en general, para contestar a todas las preguntas que carecían de respuesta (Rowe, 1946; citado por Eeckhout, pp. 164-165) (las cursivas son nuestras).

No solo la calidad es digna de relevar en esta actividad profesional, sino la naturaleza democrática de las relaciones interculturales, que hasta hoy se observa en las relaciones entre el médico andino y el paciente.

En países como México y Colombia, entre otros, existen estudios sobre el mercado de las plantas medicinales; sin embargo, la particularidad del hampiqato de nuestra localidad es diferente a aquellas.

\section{Ayacucho, una realidad de convivencia multicultural}

En la ciudad de Ayacucho se incrementó la población desde 1983. Después de más de una década de violencia, en 1992 la ciudad ya mostraba claramente una nueva distribución poblacional. Esta vez la mayoría de habitantes eran pobladores rurales establecidos en las zonas periféricas del centro urbano. Las invasiones fueron el mecanismo más práctico para conseguir terreno. Así, surgieron precarias viviendas con carencia de servicios elementales de vida, como agua, desagüe, corriente eléctrica y transporte público.

Mientras que, en la zona norte del departamento, una de cada 10 personas migraba fuera del departamento, del espacio del sur lo hacían 1,4 personas por cada 10 habitantes. Todas las provincias registraron tasas de migración neta negativas. Las provincias con mayor expulsión de población fueron Parinacochas y Vilcashuamán, con más de 40\%; Lucanas, con 33\%; y Cangallo y Huanta, con $26 \%$. Los datos del censo de 2007 dan cuenta de que la población rural representa 42\% del total departamental, pero en la provincia de Huamanga, donde se encuentra la ciudad de Ayacucho, Ilega a 36\%. En el nuevo espacio de sobrevivencia los conocimientos ancestrales se recrean (Li, 1992, p. 19).

Los migrantes comparten toda su cultura cuando llegan a la ciudad de Ayacucho. Es así que, cuando se presentan problemas de salud, las formas 
de entenderlas y resolverlas emergen del habitus ${ }^{5}$ de la memoria ancestral. En un gran sector de los migrantes de primera y segunda generación, hoy continúan reproduciéndose las percepciones ancestrales sobre salud y enfermedad.

Las familias procedentes de las zonas rurales más alejadas del departamento, en su mayoría analfabetas, quechuahablantes y con creencias propias respecto al proceso salud-enfermedad, nos dieron la oportunidad de constatar que permanentemente preferían la atención de los curadores (hampiq) para restablecer sus males; estos especialistas, mediante el uso de recursos naturales (animales, vegetales y minerales) y ritos, previenen diagnostican y curan los síndromes culturales (Icochea, 2012, p.15).

Desde fines del siglo XX, la ciudad de Ayacucho se convirtió en el escenario de prácticas y procedimientos culturales diferentes de los de una ciudad provinciana del interior del Perú, donde muchas pautas de conducta tenían su soporte en los modos de vida local: fuerte arraigo a las festividades religiosas, relaciones sociales de tipo patriarcal, consumo de muchos productos del lugar; en fin, una vida cuasi rutinaria.

\section{Hampiqato y uso alterno de medicamentos}

La globalización ha generado la proliferación de muchos sistemas alternativos de salud en nuestra sociedad. No solo el espacio urbano es el escenario de múltiples ofertas para restablecer diferentes males de salud: también los pequeños poblados del espacio rural son testigos de estos cambios. El hampiqato, a diferencia de la proliferación de muchos sistemas alternativos de salud, continúa manteniendo su particularidad a través del tiempo por ser una herencia cultural de nuestros antepasados.

5 Para Bourdieu (1997, p. 141), habitus es un sistema de disposiciones duraderas, transferibles; son estructuras estructuradas, predispuestas para funcionar como estructuras estructurantes, como principios generadores y organizadores de prácticas y representaciones que no obedecen a algo regulado ni orquestado [...] el habitus hace referencia a aquello que se ha adquirido y se incorpora en el cuerpo de manera duradera. 


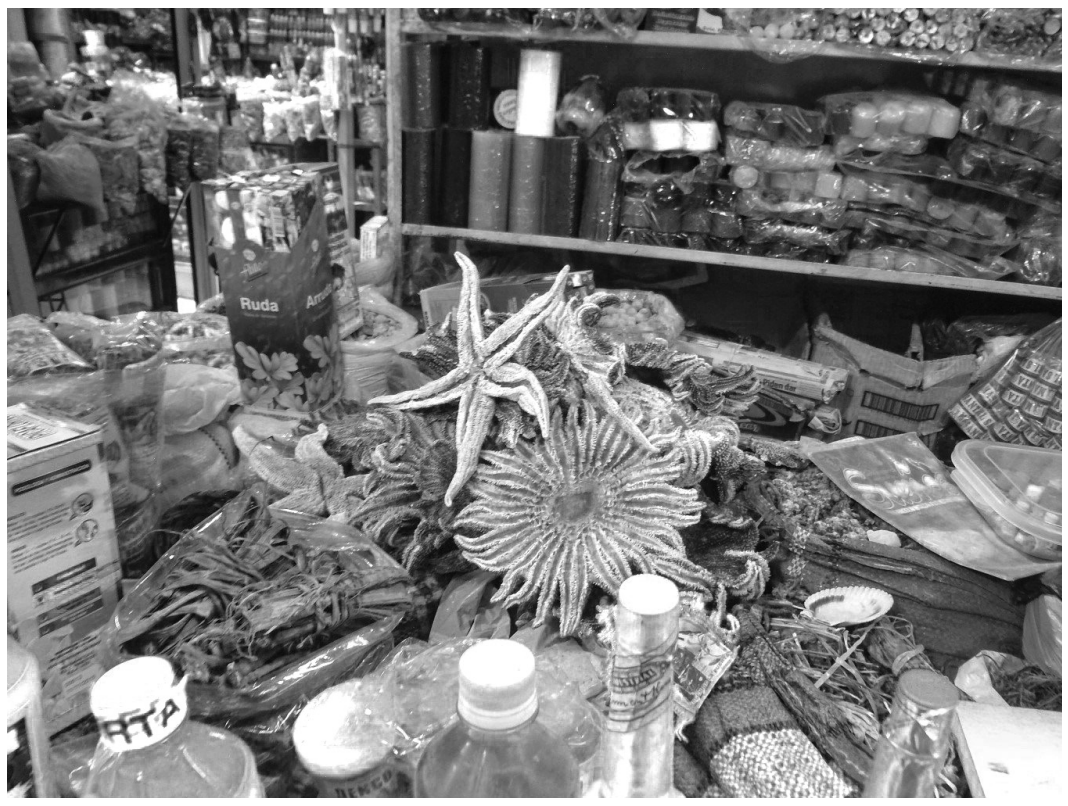

FIGURA 1.

Algunos recursos naturales en un quiosco del mercado Carlos F. Vivanco de Ayacucho.

Archivo de W. Pariona, 2013.

El hampiqato, según mis abuelos, habría comenzado en la plaza de Armas de Ayacucho. Eso sería hace muchos años. Muchos años después, cuando el señor Carlos F. Vivanco regaló este lugar donde estamos [se refiere al mercado antiguo], mi mamá vendía cerca del puesto de carnes. Ya después nos ubicamos aquí. Yo trabajé ayudando a mi mamá desde los seis años. Aquí vendemos remedio para muchas enfermedades. Por ejemplo, tenemos para wayra, puquio waspi, Pachamama. Los remedios que tenemos son grasa de mula y de llama. En los vegetales tenemos ajo macho, ajo verde, huamanripa, antiajos, pachatullma, wayruru, llampu de tres colores (blanco, rojo y ocre), imán, azufre. También desde la costa nos traen conchitas hembra y macho. Las personas que nos compran vienen de todas partes (por ejemplo, desde las alturas de Huanta), pero de aquí de Huamanga también compran para curarse. Acá los remedios son naturales (R.T.V., Expendedora del hampiqato, 2013).

Es probable que, durante la época colonial, las nacientes ciudades como Ayacucho hayan sido el escenario público de la venta de hampi (vocablo quechua que alude «a todo lo que es medicamento o recurso natural para curar»), ya que la sociedad colonial, por su carácter estratificado y racista, se mostró indiferente ante los problemas de salud pública de los sectores dominados. En ese contexto, los pobladores indígenas y desposeídos tuvieron como recurso los medicamentos del hampiqato. 
Desde fines del siglo XX, de manera lenta, el proceso de cambios en la oferta de medicamentos también involucra al tradicional hampiqato. Por eso en la actualidad todos los puestos existentes en los mercados de abastos de Ayacucho ofertan algunos medicamentos procesados provenientes de la capital Lima.

Desde hace cinco años nos abastecen con aceites y esencias en frasquitos, aunque la timolina y el agua del Carmen y agua de azar ha habido, pero hay muchas cosas que ahora ya vienen preparadas (R.T.V., 2013).

En el hampiqato de la localidad se puede apreciar una gran diversidad de productos de origen vegetal como el huayruru (Ormosia sp. Ormosia anmazónica, Duker). Estas semillas son conocidas como hembra y macho, y las primeras son las más menudas. Otro tipo de semillas son la del cuti (Prosopis strombulifera), clasificada en hembra y macho; pachapa pupun, una variedad de liquen cuyo nombre científico desconocemos; pacha lacre, huillca, Piptadenia colubrina (vell) benth, semillas clasificadas en macho y hembra; hatun cuti, Cariocar sp., semillas clasificadas en macho y hembra, entre muchas otras. El conjunto de recursos vegetales proceden de diferentes altitudes y regiones del territorio peruano. Existen también los de origen animal, como las estrellas de mar y conchas marinas clasificadas en macho y hembra.

La clasificación en macho y hembra estaría relacionada con la complementariedad de elementos diferentes. En la cosmovisión andina, por ejemplo, varón y mujer son géneros diferentes pero complementarios. Asimismo, los insumos o recursos de origen mineral son muchos, de los cuales señalamos algunos: chawa quri: calcopirita en cuarzo, con brillo similar al del oro; chawaqullqi, blenda calcopirita y cuarzo, con brillo similar al de la plata; llampu y lumbre.

Las expendedoras del hampiqato en su totalidad son del género femenino, cuidadosamente preparadas para este quehacer. Como las farmacéuticas de los establecimientos de medicamentos modernos de la ciudad, las personas que atienden en el hampiqato conocen muy bien su oficio. 


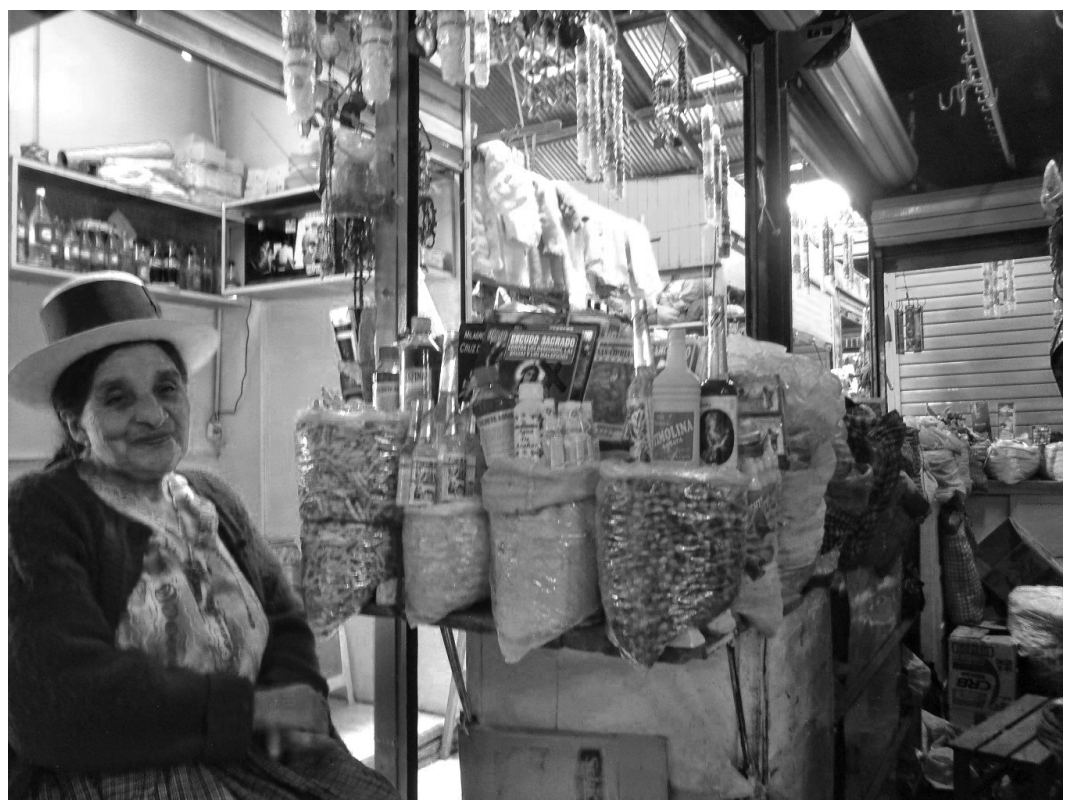

FIGURA 2.

Propietaria de uno de los quioscos del hampiqato.

La bolsa de la derecha contiene huayruru (Ormosia sp. Ormosiam anmazónica, Duker).

Archivo de W. Pariona, 2013.

Yo trabajo desde los 12 años. Tengo más de 70 años. Soy analfabeta. Este negocio lo aprendí con mi mamá. Ella vendía aquí. Ella me enseñaba para qué sirve cada remedio y cómo se preparan las misas [se refiere a la parafernalia de recursos naturales que expenden convenientemente preparado, teniendo en cuenta la naturaleza, las bondades, el tamaño y el número de cada recurso natural]. Ahora, las vendedoras más jóvenes ya no saben como nosotras... Los campesinos siempre nos buscan a las mayores, porque nos conocen y saben que todo lo que piden lo hacemos de manera adecuada; es decir, sabemos qué remedios se requiere para cada enfermedad... A veces recetamos algunas cosas que sabemos desde mucho tiempo. Acá no vendo esas cosas que vienen de Lima y ya no son naturales. Aquí, por ejemplo, tengo medicamentos para la pacha, el pronco [se refiere a los males broquiales] y mancharisqa. Yo no sé dónde se habría iniciado el hampiqato. Yo recuerdo que siempre estuvo en este mercado. Aquí viene toda clase de personas (C.T.V., expendedora del hampiqato, 2013).

La actividad de las expendedoras del hampiqato, en todos los casos, es una herencia de sus antecesores cercanos. Por ser recurrente este tipo de afirmaciones, tentativamente, decimos que esta tradición podría ser la actividad estrechamente relacionada con los servicios de los antiguos 
hampicamayoc, quienes requerían de este tipo de establecimientos adecuadamente organizados. Aquellas personas dedicadas a acopiar, seleccionar y ofrecer los medicamentos debieron ser preparadas, cuidadosamente informadas de los valores medicinales de los recursos naturales. Según Cabieses, el hampicamayoc y chukrihampicamayoc de la época inca podrían haber sido el médico y el cirujano, respectivamente; sin embargo, desconocemos la denominación de los antiguos expendedores de recursos medicamentosos. En cambio, todo médico tiene como función prevenir, diagnosticar y tratar las enfermedades, pero no es quien expende la gran variedad de medicinas, por lo que es lógico que los dispensadores del hampiqato tengan una larga tradición como los hampicamayoc.

La probabilidad de su verdadera existencia como médicos y cirujanos de la élite incaica queda un poco oscurecida por el silencio de la mayoría de los cronistas, que dejan de mencionarlos entre los numerosos tipos de profesionales que practicaban la mezcla de actos curativos y religiosos que constituían lo que hasta ahora estudiamos como medicina peruana precolombina (Cabieses, 2007, p.159)

Es evidente que el etnocentrismo de los españoles no les permitió aceptar la existencia del sistema médico andino, que funcionaba perfectamente en la prevención, el diagnóstico y el tratamiento de las enfermedades de la antigua sociedad andina.

Cada vez hay más gente que viene a comprar al hampiqato. Desde hace como tres años nos traen remedios en frascos; traen de Lima y del norte. Los hampiq a quienes nosotras conocemos son los que recetan los remedios que deben comprar aquí, indican, pero nosotras también les decimos cuáles son. Así nos damos cuenta de que no son los auténticos. Nosotras ya conocemos los remedios adecuados para una enfermedad. Pero yo no soy curandera, no. También existen los malos curanderos, que no saben bien. A veces vienen a preguntar qué remedios pueden comprar para una determinada enfermedad y nosotras ya los conocemos, son a la vista (C.T.V., 2013).

El testimonio precedente es coherente con nuestra hipótesis sobre el dispensador del hampiqato: son profundos conocedores de las propiedades de los recursos medicinales naturales.

Los médicos andinos de la época inca se clasifican en un gran número de especialistas; así, unos se denominaban sonccoyoc (especialista en males del corazón), allcos (los que convocaban a los dioses), mosccos (preparados para interpretar los sueños), cuyricuc (los que diagnosticaban enfermedades usando el cuy), pachacuc (los que diagnosticaban enfermedades, observando el movimiento de arácnidos), ayatapuc (los que se comunicaban con el espíritu de los 
muertos), hechecoc (adivinaban enfermedades previa ingestión de coca y tabaco), caviacoc (diagnosticaban enfermedades ingiriendo bebidas alcohólicas), hachus (hacían diagnósticos usando granos o excremento de animales), virapiricus (diagnosticaban observando el humo sobre la grasa de llama), calparicuc (observaban los males sacrificando animales)» y muchos otros que no es nuestro propósito analizarlos. Sin embargo, refiere que existían curanderos [sic] denominados camascas (Cabieses, 2007, pp. 152-159).

Consideramos que es un error producto de sus reflexiones desde el punto de vista técnico como profesional médico, y su enfoque evidencia un fuerte sesgo occidental, porque la denominación de curandero aparece en los primeros estudios sobre la nosografía indígena de comienzos del siglo XX.

Por otro lado, en México, los estudios sobre la medicina y otras tradiciones denominadas indígenas datan desde la década de 1980, por lo que existe abundante bibliografía producto de los hallazgos etnohistóricos. "La especificidad de la cultura indígena radica en su herencia mesoamericana, tradición cultural que pese a los siglos de dominación sigue caracterizando a la población indígena. La cosmovisión mesoamericana tuvo como fundamento central el medio ambiente y su interacción constante con él. Esto se debió a que fue una sociedad que fundamentalmente basó su subsistencia en la agricultura, lo que la hacía altamente dependiente de los fenómenos naturales» (Gámez, 2009, p. 80).

\section{Cosmovisión y resistencia del imaginario andino}

La existencia del hampiqato como hecho cultural de nuestra realidad no está desligada de la cosmovisión de los pobladores usuarios que demandan de ella. No existe un solo concepto de cosmovisión debido a la diversidad cultural de nuestro país y de América para este estudio; sin embargo, presentamos un concepto que nos parece adecuado:

En la cosmovisión de un pueblo se sintetizan de manera estructurada sus principales conceptos acerca de la forma y calidad del universo, de sus habitantes y la posición del hombre dentro de ese sistema. Sobre todo en culturas tradicionales, la cosmovisión sirve de modelo para varios aspectos de la cultura, como el patrón de asientos de los poblados, la organización de la sociedad y ritos de mucha índole. Por esto la cosmovisión influye de varias formas la vida rutinaria del pueblo respectivo (Kohler, 1980 p. 583, citado por Martínez).

En el plano social organizativo, los pobladores andinos consideran a la naturaleza como componente vivo de su entorno y este ejerce permanente influencia en su existencia. La enfermedad afecta al individuo cuando este descuida o comete negligencia al trastocar la relación armoniosa con 
la naturaleza y su entorno social. Para comprender mejor lo que afirmamos, presentamos el siguiente testimonio:

Una vez me adjudicaron una plaza docente en el campo y tuve que viajar hasta la localidad de Corralpampa (distrito de Paras, provincia de Cangallo). En mi viaje, cada vez que me cansaba yo me recostaba en el suelo, en cualquier lugar. Al cabo de dos semanas, me sentí mal, tuve desvanecimiento. Por las noches no podía dormir, tenía malestar, hincones por todo el cuerpo; tenía ganas de llorar y lloré, pero luego tuve que ir al médico del hospital. Mi diagnóstico fue problema neurológico y para esto me recetaron pastillas; yo tomé, pero no sentía mejoría. Mi cuñado me dijo que tenía estrés, pero yo no me sentía así; hasta que una persona que vino a mi tienda y escuchó lo que le conté de mi mal me recomendó que fuera al camal de Ayacucho para que me «entierren en la panza de vaca» [bazofia, pasto engullido por el vacuno y que aún no está procesado para su digestión]. Eso hice. Cuando en el camal ya me habían cubierto todo el cuerpo con la «panza de vaca», las personas que debían soplarme con humo de cigarrillos tuvieron que masticar previamente la coca. Luego, con cuidado, me sacaron envuelta en mi frazada. Así tuve que permanecer por tres días en mi casa. Al cabo del tercer día sentí un poco de mejoría. Pasó como un mes, y como no me sentía totalmente sana, me fui a buscar a un curandero en Carmen Alto. El curandero me diagnosticó pacha; me dijo que el cerro me había cogido y mi tratamiento requería del pampapu [ofrenda para la Pachamama]. Para esto me indicó un cuye [sic] que compré en el mercado. Además, todas las cosas para el pampapu tuve que comprarlas en el hampiqato del mercado Carlos F. Vivanco, porque las que venden allá ya tienen toda la mesa preparada. Con todo esto, el curandero prendió las velas que llevé y las plantó en el piso de mi cuarto. También ahí, sobre un mantel, pusieron la coca y las flores de clavel. Luego comenzaron a masticar coca con su ayudante, que era otra curandera. Después de beber un poco de aguardiente de caña, me pasaron el cuye por todo el cuerpo. De rato en rato, soplaban humo de cigarrillo sobre mi cuerpo. Era de noche. Una vez que me pasaron el cuye y todas las cosas que había comprado en el hampiqato, lo envolvieron todo y se fueron. Me dijeron que llevarían todo al cerro. Después de este tratamiento a los pocos día comencé a recuperar mi salud; yo no creía, ahora estoy sana (B. testimoniante, 2013).

En el relato precedente, se aprecia cómo la medicina oficial no siempre diagnostica el mal que sufre el paciente, por lo que el enfermo busca al médico andino, quien, con su valioso conocimiento, restablece la salud del enfermo empleando necesariamente los recursos naturales que se adquiere en el hampiqato. 
La testimoniante, hoy profesora cesante, pudo haber insistido en curarse con la atención médica del Hospital de Huamanga o algún médico particular; sin embargo, los síntomas característicos de su mal que ella conoce la condujeron a buscar el otro sistema de salud. El hecho de acudir al hampiq (conocido por muchos hispanohablantes como curandero), desde el punto de vista cultural, es la expresión de la vigencia de la racionalidad andina. El proceso aculturador de la escuela o el de la profesionalización, como en este caso, no es obstáculo para que el contexto de una sociedad con creencias, mitos e imaginarios de origen ancestral influyan o reaviven muchos aspectos de la cosmovisión, porque es la cosmovisión de origen andino la que sigue marcando las pautas de conducta de muchos habitantes.

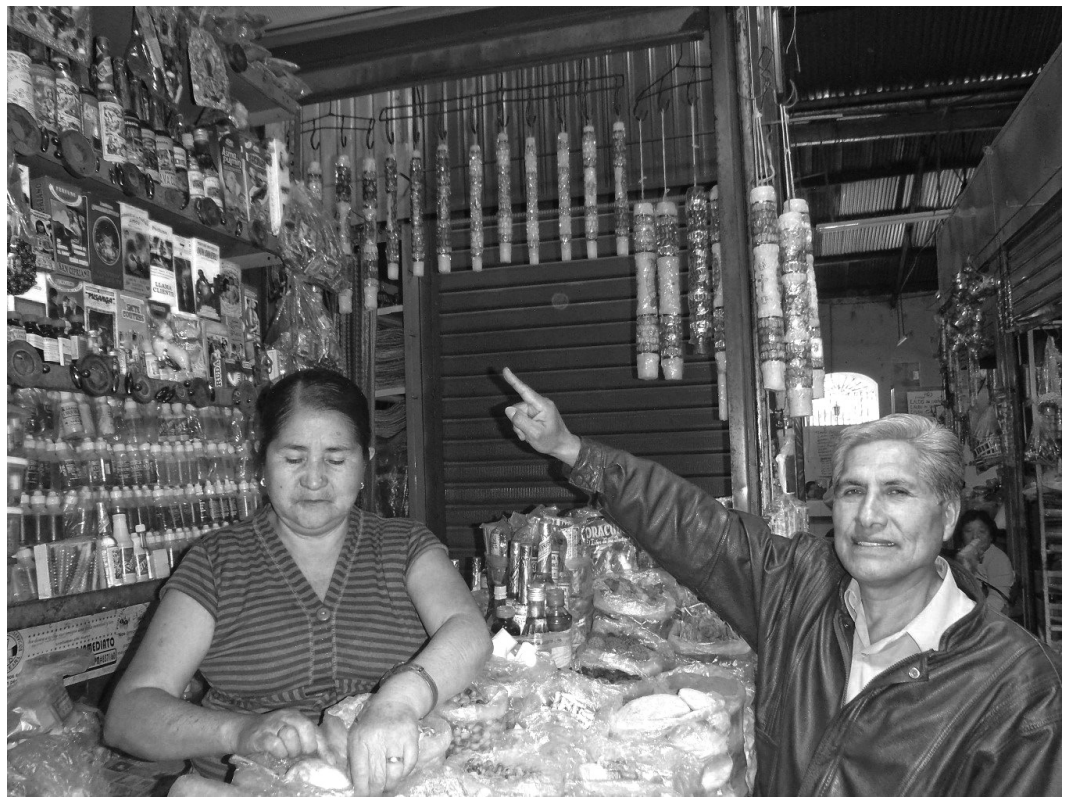

\section{FIGURA 3.}

Hampiqato del mercado Andrés F. Vivanco. En la parte alta se muestran los actuales productos procesados provenientes de la ciudad de Lima.

Archivo de W. Pariona.

\section{Hampiqato, tradiciones culturales y salud}

Cuando aludimos a la idea de tradición no estamos pensando en todo lo que ocurrió y quedó anclado en el pasado. Por lo contrario, nos referimos a todo proceso cultural que habiéndose desarrollado en el pasado aún funciona reelaborado de manera actualizada y vital. La gran diversidad cultural del Perú nos ha legado un grandioso mosaico de tradiciones en el campo de la salud-enfermedad. 
Las tradiciones representan la ordenación de la materia bruta del pasado: se recuerdan algunas cosas y otras se olvidan a propósito, pero todo está estructurado de tal manera que el pasado viene a tener significado. El entendimiento y el significado son ellos mismos - como dice Gadamer - fundamentados y condicionados por las tradiciones específicas dentro de las cuales han sido entendidos de un modo concreto. La tradición, pues, condiciona tanto la manera en que podemos entendernos como la sustancia de lo que es entendido (Sanders, 1991, p. 137).

No solo las formas de entender la salud-enfermedad, sino muchos de aquellos recursos o insumos que emplea la medicina tradicional hoy día, resisten, claro está, con muchos cambios. Todo aquello que deja de tener significado y no funciona desaparece y queda definitivamente en el olvido, y deja de ser parte de la tradición. Esto no ocurre con el hampiqato de la ciudad de Ayacucho.

\section{Simbolismo y realismo del hampiqato}

Los seres humanos han creado los símbolos para comunicarse, interactuar y orientarse en la sociedad. Como creación cultural, los símbolos constituyen el soporte de nuestra existencia: «El símbolo es el fundamento de todo cuanto es. Es la idea en su sentido originario, el arquetipo o forma primigenia que vincula el existir con el ser. Por él, a modo de puente, el ser se manifiesta a sí mismo: crea un lenguaje, inventa los mundos, juega, sufre, cambia, nace y muere. Pues precisamente por el símbolo la existencia y la realidad del mundo sucesivo dejan de ejercer su tiranía sobre la mente» (Chevalier y Gheerbrant, 1986, p. 230).

Cuando mi hijita se enfermó la llevé a diferentes médicos, pero no mejora, no sé qué tiene, no tiene fuerzas en su cuerpito. El doctor N. me dijo que requiere rehabilitación. El año pasado en noviembre fui a Lima para la rehabilitación. Allá me enteré de un curandero que vio en el tarot y me dijo que a mi hijita tiene que tratarla un curandero. Por eso en febrero de este año busqué al señor Lucio. Él hizo la curación en mi casa, le pasó con huevo varias veces, [pero] en realidad no mejoró nada. Por las noches le dio como una especie de desmayo. El curandero me dijo que es aire y por eso me recetó que en el hampiqato compre un preparado y eso le hacíamos tomar a mi bebe; con esas hierbas mejoró un poco, por eso vengo donde este otro señor curandero (D., usuaria del hampiqato, 2013).

Para muchos pobladores de la ciudad y el espacio rural ayacuchano, el hampiqato es la «farmacia ancestral» que simboliza el poder y la eficacia de ciertos medicamentos que no existen en las farmacias modernas de la ciudad de Ayacucho. Como sostiene Taipe (2006, p.7), entre la realidad y 
el símbolo existe una relación dialéctica. El símbolo produce la realidad, pero al mismo tiempo es producido por ella.

Toda cultura produce y entiende el significado de sus símbolos, porque los símbolos son elementos relativamente estables de la continuidad cultural; nunca pertenecen a un solo corte sincrónico de la cultura, siempre atraviesan ese corte verticalmente, viniendo del pasado y proyectándose al futuro. Como ente viviente, el símbolo tiene una doble naturaleza: es invariante y variante (recibe la influencia de su contexto cultural, pero al mismo tiempo lo transforma) (Lotman, 1993, p. 7, citado por Taipe).

Cuando nosotros señalamos la naturaleza simbólica del hampiqato, no pensamos en una realidad ficticia; mucho menos concebimos que aquel espacio es una simple representación de lo que ocurrió hace mucho tiempo. Usamos la categoría símbolo para evocar aquel grandioso conjunto de conocimientos científicos sobre las propiedades medicinales de plantas animales y minerales debidamente comprobadas y validadas por nuestras culturas andinas, y que aún hoy se recrean para la sociedad ayacuchana. El hampiqato de hoy, para algunos habitantes de la ciudad, tal vez no represente lo que señalamos, porque desconocen nuestra historia pasada. Las personas desinformadas asumen que la ciencia positivista predominante, es decir, la modernidad y la tecnología de punta son las únicas capaces de producir medicamentos para restablecer todo tipo de enfermedades.

El símbolo es, pues, una representación que hace aparecer un sentido secreto; es la epifanía de un misterio (es decir, la aparición de lo inefable). La parte visible del símbolo, el significante, siempre estará cargada del máximo de concretes y, como bien dijo Paul Ricœur, todo símbolo auténtico posee tres dimensiones concretas: es al mismo tiempo cósmico (es decir, extrae de lleno su representación del mundo bien visible que nos rodea), onírico (es decir, se arraiga en los recuerdos y los gestos que aparecen en nuestros sueños, y que constituyen la materia más concreta de nuestra biografía íntima) y, por último, poético (o sea que también recurre al lenguaje más íntimo, por tanto el más concreto (Durand, 1971, p. 15).

La primera dimensión del símbolo es el cósmico. Esta abstracción refuerza nuestra afirmación de que lo simbólico no es representación de lo irreal; todo lo contrario, representa todo lo que está (y estuvo en la cultura de nuestros antepasados) en la realidad objetiva. En esos términos, señalamos que, para las personas que necesitan del hampiqato y los que lo conocemos, este espacio es una realidad cargada, eso sí, de «misterio», porque sus orígenes se pierden en nuestro pasado remoto. En la vida real 
de muchos pobladores de la ciudad de Ayacucho, el hampiqato constituye el soporte más importante de la medicina ancestral.

\section{Hampiqato, patrimonio vital de Ayacucho}

Toda creación y producción culturales que recrean, reelaboran y actualizan los valiosos aportes de nuestros antepasados son considerados pertenencia valiosa de la sociedad que los necesita y reclama. Considerar patrimonio de nuestra cultura al hampiqato no es apegarnos al pasado idílico ni expresar sentimientos nostálgicos sobre un componente fundamental de la medicina tradicional de origen ancestral. Todo lo contrario, como investigadores de los procesos de salud y enfermedad, nuestra misión es acopiar información de la realidad fáctica, analizar, interpretar y explicar su vigencia.

El hampiqato es una realidad vigente, símbolo de valiosos aportes y conocimientos de los recursos naturales que se usaron en el pasado y se usan hoy para aliviar y curar muchas enfermedades, no solo los denominados síndromes culturales; la efectividad de los recursos naturales que se expenden en el hampiqato están asociados y dependen de la performance de los auténticos operadores de la medicina tradicional, los actuales hampiq (médicos andinos) de Ayacucho y del país.

\section{Conclusiones}

1. En un contexto cultural diverso y de cambios permanentes en nuestra sociedad, muchos habitantes de la ciudad y del espacio rural de la provincia de Huamanga acuden al hampiqato a fin de proveerse de insumos para restablecer sus males de salud.

2. Los testimonios de los pacientes de la medicina tradicional refieren, en su totalidad, que usan los insumos del hampiqato cuando tienen necesidad de prevenir, diagnosticar y tratar sus enfermedades.

3. El hampiqato o «farmacia ancestral», como espacio simbólico ubicado en el mercado Carlos F. Vivanco de la ciudad de Ayacucho, representa la recreación y reelaboración permanente de muchos recursos naturales heredados por nuestros antiguos antepasados.

4. Lo simbólico de este espacio no significa que sea una representación ficticia. Por el contrario, es la expresión vital de nuestra tradición andina que ofrece valiosos insumos medicinales largamente comprobados y cuya eficacia fueron validadas evidentemente.

5. La medicina tradicional tiene permanente stock de medicamentos en el hampiqato de la ciudad de Ayacucho y, por su gran importancia, bien puede ser considerado patrimonio vital de nuestra sociedad. 


\section{REFERENCIAS BIBLIOGRÁFICAS}

Bourdieu, P. (1997). Razones prácticas sobre la teoría de la acción. Barcelona: Editorial Anagrama.

Cabieses, F. (2007). La salud y los dioses. La medicina en el antiguo Perú. Lima: Fondo Editorial de la Universidad Científica del Sur.

Chevalier, J. y Gheerbrant, A. (1986). Diccionario de los símbolos. Barcelona: Editorial Herder.

Durand, G. (1971). La imaginación simbólica. Buenos Aires: Amorrortu Editores.

Editorial Septiembre (2015). Hacia la primera civilización de América. Lima: Editorial Septiembre.

Eeckhout, P. (2008). El oráculo de Pachacamac y los peregrinajes a larga distancia en el mundo andino antiguo. En Curatola, M. y Ziolkowski, M. (Eds.). Adivinación y oráculos en el mundo andino antiguo (161-180). Lima: Fondo Editorial de la Pontificia Universidad Católica del Perú.

Gámez, A. (2009). El cerro troje: cosmovisión, ritualidad, saberes y usos en una comunidad Ngiwá del sur de Puebla. Cosmovisión mesoamericana y ritualidad agrícola. Estudios interdisciplinarios y regionales. México D. F.: Dirección de Fomento Editorial de la Benemérita Universidad Autónoma de Puebla.

Icochea, G. (2004). Medicina tradicional y enfermería intercultural en Ayacucho. Huancayo: Naokim Editores.

(2012). La enfermería y la interculturalidad en salud en el Perú. Alteritas, 1, pp.15-26.

Li, D. (2009). Ayacucho: Análisis de situación en población. Lima: Consorcio de Investigación Económica y Social.

Lumbreras, L. (2006). El papel del estado en el campo de la cultura. En Cortés, G. y Vich, V. (Eds.). Políticas culturales. Ensayos críticos (pp. 71-111). Lima: Instituto de Estudios Peruanos, Instituto Nacional de Cultura y Organización de Estados Iberoamericanos.

Martínez, C. (2004). El círculo de la conciencia. Una introducción a la cosmovisión indígena americana. En Llamazares, A. y Martínez Sarasola, C. (Eds.). El lenguaje de los dioses: arte, chamanismo y cosmovisión indígena en Sudamérica (pp. 21-65). Buenos Aires: Editorial Biblos.

Pedersen, D. (2009). Globalización, salud y sistemas médicos andinos. En Sánchez, R. y otros (Eds.). Medicina tradicional andina. Planteamientos y aproximaciones. Cusco: Centro de Medicina Andina y Centro de Estudios Regionales Andinos Bartolomé de las Casas. 
Sanders, K. (1997). Nación y tradición. Cinco discursos en torno a la nación peruana, 1885-1930. México D. F.: Fondo de Cultura Económica.

Taipe, N. (2007). El símbolo: acepción, diferencias y definición. Ayacucho: Escuela de Formación Profesional de Antropología Social de la Universidad Nacional San Cristóbal de Huamanga.

Zolla, C., Del Bosque, S., Tascón, A., Mellado, V. y Maquoe, C. (1988). Medicina tradicional y enfermedad. México D. F.: Centro de Estudios de Seguridad Social.

Recibido: octubre de 2015

Aceptado: diciembre de 2015 